\title{
Empathies of Musical Performance and Understanding
}

\author{
ANTON VISHIO \\ William Paterson University
}

\begin{abstract}
In my commentary on Erin Heisel's thought-provoking essay, I explore alternative responses to the masterclass she describes. I propose expanding the kinds of empathy that might be most useful to performers to include cognitive empathy, while suggesting ways in which an empathy of identification can be problematic. I consider as well expansions to her definition of empathy to engage considerations of musical structure and embodiment, and I close with a proposal to expand Heisel's pedagogical techniques into situations where empathy may be hardest to find.
\end{abstract}

Submitted 2014 October 13; accepted 2014 October 29.

KEYWORDS: cognitive empathy, embodiment, performance

WHILE numerous studies of emotion and empathy in music from the standpoint of the listener have appeared of late, ones that explore how performers construct empathic performances have been fewer, and ones that do so with pedagogical guidance seem rare indeed. Erin Heisel has provided a valuable resource from her perspective as a skilled performer and music analyst. In my reply, I shall take two of her reflections, about the example of the masterclass and about the nature of empathy in vocal performance, in somewhat different directions, but I want to register at the outset my admiration for her challenging contribution.

\section{MANON IN THE MASTERCLASS}

What lessons should we draw from the lifeless performance of the Gavotte from Manon? On the one hand, I agree with Heisel that the student's one-dimensional approach to the character contributed to an unsatisfying musical experience; on the other, I am less sure of the diagnosis that a lack of emotional identification is the main culprit. Heisel does draw from the situation some important reflections on what it means to portray characters that one might hardly emulate in real life. And yet, one is struck by the conflict between the student's emphatic pronouncement that the character was a "whore" and the virtually flat affect of her performance. Is it possible that where the student needed guidance was not in how to find something - anything - sympathetic in her character, but rather in how to channel her evidently passionate disapproval in a constructive direction?[1]

In this instance, the singer might be advised to take into account the range of her character's own feelings towards her behavior. A Manon who reflects bitterly on her inability to resist "the tempter's voice" at the end of Act II, a Manon who sings in full penitent mode to her hapless beloved, des Grieux, just before her death, "Ah! would that I could now atone with all my blood for but one of the griefs you have endured through me!": this is a thoughtful Manon, capable of realizing that her persona in Act III betrays something deep inside her, one whose joy in that moment may well not be unalloyed - and one who in the end might adopt for herself some nuanced version of the student's harsh judgment.

I am not advocating a particular interpretation; I mean only to suggest a possibility within the reach of the masterclass participant. What I am describing is still in some sense an empathetic performance, only one that primarily makes use of cognitive empathy, described by Bloom (2014) as "the more coldblooded process of assessing what other people are thinking, their plans, what they believe," or more simply as "perspective taking" (Preston \& de Waal, 2002), rather than emotional empathy, an empathy of identification (within the "boundaries" that Heisel carefully sets out). More generally, it seems to me that arguments parallel to Bloom's against emotional empathy as a guide to moral action can be constructed against emotional empathy as a guide to musical performance: for example, just as an empathy of identification can be biased in favor of those who are most like ourselves, so too can empathy in preparing 
a performance lead us to highlight the things about a character that are most like us, creating a potentially distorted or incoherent view of that character.[2] Reflecting on this and other parallels, a singer might approach empathic identification more cautiously, even and especially when that comes easily for a given role.

\section{MANY EMPATHIES}

That said, the perspective of the performer and the audience may be quite different; where the performer might interrogate her empathic identification with a given character, an audience member might instead take considerable pleasure in imagining just such an identification with the singer, the persona she projects, or both-although the capacity of an audience to imagine can go beyond even the presence of a particular representational content on stage (Walton, 1994).[3] As one of several components that make up empathy for vocal performance, Heisel identifies "audience experience"; perhaps "audience interaction" would be a better fit, since "audience experience" runs the risk of making it seem that the same kind of empathic process is involved, that there is a seamless join connecting a performer's attitude towards a character with an audience's reception of that character.[4]

Further, despite the comprehensiveness of her definition, I miss the sense of a specifically musical component to her picture of empathy, one that might be shared by instrumental performance as well. It is clear when she encourages students to explore the question: "What sorts of things does the music tell us about a character that the text and story do not?" that such musical (or better music-analytical) considerations remain of vital importance, something well on display in her earlier study of songs by David Del Tredici (Heisel, 2013). I mention this not so much to point out a deficiency, but rather because it might suggest that instrumental performers have nothing to learn from her approach, a claim with which I am sure she would disagree. In fact, Robinson and Hatten (2012) already suggest ways in which aspects of vocal performance might be instructive more generally; they note that "it is probably largely because song is typically an expression of emotion in a persona that the idea arose that non-vocal music could also be such an expression" (p. 78), and later that "the (topical) adoption of vocal genres in instrumental music is one way in which a purely instrumental work can appropriate the expressive power of a persona" (p. 90).

The relationship between vocal and instrumental performance is of course never so intimate as it is in the art song repertory; here, beyond the basic conditions of performance, where presumably vocalist and pianist should be in some personal sympathy with each other, there are interesting cases of empathic mismatch. For instance, in an analysis of Schubert's song "Ihr Bild," from the song cycle Schwanengesang, Lewin (2006) entertains an interpretation in which the short piano epilogue seems to challenge the singer's state of denial: "After 'I cannot believe that I have lost you,' the piano clearly states: 'But you have lost her"' (p. 138). Lewin then goes on to consider how the singer should act during this epilogue, based on whether or not the singer "hears" the final verdict of the pianist. If the verdict is heard, the singer may well act as though shattered by the lack of empathy the accompanist displays; alternatively, the singer might feel little empathy with his or her own persona, and feel that the critique articulated in the accompaniment, as grim as it is, is a more honest assessment, or indeed remain blissfully ignorant of the pianist's trenchant remarks. These all represent different kinds of identification or non-identification between the conflicting personas of the singer and pianist; yet, whatever their emotional-empathic allegiances, it would seem advisable for the two performers to adopt a common cognitive-empathic interpretation in order to project a coherent drama.

\section{Empathy and Embodiment}

Heisel's suggestion that "singers who allow natural physical responses to emotions experienced by a character, in the forms of gestures, for example, may find the doing of these actions leads to deeper empathic engagement" (2015, p. 105) seems just right, and accords with my own experience as a pianist; I well recall my piano teacher in college, Glenn Jacobson, counseling me on how to move to help mark an important cadence in a Mozart concerto. I agree that this technique may be put in the service of Schechner's (1990, p. 41) "doing of the action of a feeling"; but it may also facilitate other kinds of empathic discovery, along the lines of what Mead (1999), following work by Cusick (1994) among others, terms "kinesthetic empathy, an identification with the embodiment of a sound" (p. 10). Two excellent resources that seem particularly germane are the study by Vines et al. (2006) which examines reactions to a 
performance of the second of Stravinsky's Three Pieces for Clarinet Solo, and the recent book by Rahaim (2012) on gestural practice in North Indian vocal music. Vines et al. are concerned with "ways in which visual and auditory information, separately and together, convey emotion (as indexed by tension) and structure (as indexed by phrasing)" (p. 107; emphasis in original). Rahaim attends to the musicking body through "a study of spontaneous gestural action that is coperformed with spontaneous vocal action: tracing curves in space, stretching virtual materials, sculpting visual objects"; he notes that "gesture complements vocal action without duplicating it, revealing knowledge about the shape, texture, and motion of melody" (pp. 3-4). These works provide yet another kind of strategy to suggest to a student needing to get inside a role that she or he is unable to sympathize with otherwise.[5] Still, this is not intended to replace any terms of Heisel's definition, but to supplement them in keeping with her goal of enhancing "empathic response to yield greater understanding" (Heisel, 2015, p. 6).

\section{PERFORMERS AND PREFERENCES IN CONFLICT}

I conclude by returning once more to the masterclass to explore another direction of inquiry it suggested to me: namely, how can one convincingly perform a work in which one is not emotionally invested - which one perhaps dislikes, in part or whole?[6] What indeed is the process of learning such a work? This is not merely a theoretical worry; there might be any number of contexts in which one might encounter such a situation - including high-pressure situations like auditions or masterclasses. And of course, it is certainly not the case that one always comes to like-or perseveres in liking - something that one is bound to perform for whatever reason. The process of journaling that Heisel describes might prove to be especially useful in this instance, to help students work their way through the experience with an empathy of understanding, if not one of identification.

\section{NOTES}

[1] In other circumstances, one might wonder if the singer's frustration with the role could relate to a disapproval not of the character but rather of the character's fate, or the limited choices she has available, due to plot, narrative convention, etc.; one might then be able to explore how to develop a kind of conspiratorial empathy - the singer and her character "conspiring" to make the best of the lot the composer and librettist have assigned them. In this way, Heisel's "wishing the character had chosen differently" (2015, p. 107) becomes something like "wishing the composer had allowed the character other options." I do not suggest that this was behind the singer's attitude here, but it is not hard to imagine other settings where such feelings could come into play and be put to productive use.

[2] In his contribution to the Boston Review forum, Jesse Prinz provides a particularly cogent summary of arguments against emotional empathy as a moral guide (Prinz, 2014).

[3] In this connection, Elizabeth Hoffman's recent article (2012) on referentiality in some recent works of computer music is suggestive, exploring ways of identification with music in which no performer (human, anyway) is present, yet one or more narrators can be imagined. More radically, thinking about our ability to respond physically to music whether or not "music makers" are visible, Walton $(2002$, p. 124) suggests that we should pay attention to a level of response more fundamental than empathic identification; he posits a "somatic sensitivity to sounds," a more "direct" reaction to "feeling vibrations," "one not involving any (even implicit) cognitive processes, or recognition, or anything like motor mimicry or empathy with either a sentient being or an inanimate object."

[4] The concept of "empathic inaccuracy" developed by Keen (2006) in her study of strategies of "narrative empathy" in novels seems potentially relevant here, despite the differences in artistic terrain. She defines the term as "a strong conviction of empathy that incorrectly identifies the feeling of a literary persona" and claims that "both authors' empathy and readers' empathy have rhetorical uses which may be more noticeable when they conflict" (pp. 222-223; emphasis in original). In our terms, composers, performers, and listeners might have different investments in a character, leading to different possibilities of empathic identity, and it would be useful to avoid conflating them. Hoffman (2012) also engages with Keen's work. 
[5] It is worth emphasizing that the juxtaposition of emotion and structure in Vines et al. (2006) does not precisely map onto the distinction between emotional and cognitive empathy, at least as I understand the terms; even if developing the latter is taken as more "cold blooded," in method anyway, I see no reason it cannot lead to some insight into the emotional content of an art work and thus in its performance.

[6] Something like what I have in mind is Robert Craft's account of a performance of Hindemith's opera Cardillac that he conducted in 1967. In a diary entry, he noted that "in spite of a few patches of really wretched music, umpteen patches of indifferent music, and the composer's lack of aptitude for the theater, the opera somehow still succeeds. (Could a performer esteem a work any less than that and still perform it?)" (Stravinsky \& Craft, 1969, pp. 252-253; a later publication of excerpts from the same diary [Craft, 1994, pp. 458-459] omits the crucial parenthetical remark). Craft is clear about which parts of the work he likes and does not like, but he does not shed light on how he performed the latter, nor on how others in the company felt about the situation. (I suppose it could count as a practical consideration against this line of inquiry that a catastrophic fire ended the production's run after only one performance.)

\section{REFERENCES}

Bloom, P. (2014). Against empathy. Boston Review, (September/October 2014). Retrieved 7 July, 2015, from http://www.bostonreview.net/forum/paul-bloom-against-empathy

Craft, R. (1994). Stravinsky: Chronicle of a friendship. Nashville, TN: Vanderbilt University Press.

Cusick, S. G. (1994). Feminist theory, music theory, and the mind-body problem. Perspectives of New Music 32(1), 8-27.

Heisel, E. (2013). Good news! A new methodology for music analysis, pedagogy, practice and performance using Johan Huizinga's theory of play, including a play analysis of David Del Tredici's song cycle 'Miz Inez Sez' (Doctoral dissertation). Retrieved from ProQuest Dissertations and Theses. (Accession Order No. AAT 3553957).

Heisel, E. (2015). Empathy as a tool for embodiment processes in vocal performance. Empirical Musicology Review, 10(2), 2-8.

Hoffman, E. (2012). 'I'-Tunes: Multiple subjectivities and narrative method in computer music. Computer Music Journal 36(4), 40-58.

Keen, S. (2006). A theory of narrative empathy. NARRATIVE 14(3), 207-236.

Lewin, D. (2006). Studies in music with text. New York: Oxford University Press.

Mead, A. (1999). Bodily hearing: Physiological metaphors and musical understanding. Journal of Music Theory 43(1), 1-19.

Preston, S., \& de Waal, F. (2002). Empathy: Its ultimate and proximate bases. Behavioral and Brain Sciences 25(1), 1-20.

Prinz, J. (2014). A response to Paul Bloom “Against Empathy”. Boston Review, (September/October 2014). Retrieved 7 July, 2015, from http://www.bostonreview.net/forum/against-empathy/jesse-prinz-responseagainst-empathy-prinz

Rahaim, M. (2012). Musicking bodies: Gender and voice in Hindustani music. Middletown, CT: Wesleyan University Press.

Robinson, J., \& Hatten, R. (2012). Emotions in music. Music Theory Spectrum 34(2), 74-106. 
Schechner, R. (1990). Magnitudes of performance. In R. Schechner \& W. Appel (Eds.), By means of performance: Intercultural studies of theatre and ritual (pp. 19-49). Cambridge: Cambridge University Press.

Stravinsky, I., \& Craft, R. (1969). Retrospectives and conclusions. New York: Alfred A. Knopf.

Vines, B., Krumhansl, C., Wanderly, M., \& Levitin, D. (2006). Cross-modal interactions in the perception of musical performance. Cognition 101(1), 80-113.

Walton, K. (1994). Listening with imagination: Is music representational? The Journal of Aesthetics and Art Criticism 52(1), 47-61.

Walton, K. (2002). Two kinds of physicality in electronic and traditional music. In D. Peters, G. Eckel, \& A. Dorschel (Eds.), Bodily expression in electronic music: Perspectives on reclaiming performativity (pp. 114-129). New York: Routledge. 